\title{
Rapid quantification of hepatitis B virus DNA by real-time PCR using fluorescent hybridization probes
}

\begin{abstract}
Correspondence
Tak-Mao Chan

dtmchan@hku.hk
\end{abstract}

Received 11 September 2002

Accepted 20 January 2003

\author{
Stephen K. N. Ho, ${ }^{1}$ Wing-Cheong Yam, ${ }^{2}$ Eric T. K. Leung, ${ }^{2}$ Lei-Po Wong, ${ }^{2}$ \\ Jack K. H. Leung, ${ }^{1}$ Kar-Neng Lai ${ }^{1}$ and Tak-Mao Chan ${ }^{1}$
}

Departments of Medicine ${ }^{1}$ and Microbiology ${ }^{2}$, Queen Mary Hospital, The University of Hong Kong, Hong Kong, China

\begin{abstract}
A highly sensitive and rapid assay has been developed to quantify hepatitis $B$ virus (HBV) DNA, based on the fluorescence resonance energy transfer principle and real-time PCR, using the LightCycler and a pair of specific fluorescent hybridization probes. This LightCycler real-time PCR assay (LC-PCR) detected HBV DNA in a linear range from $10^{1}$ to $10^{8}$ copies per reaction (250$2.5 \times 10^{9}$ copies $\mathrm{ml}^{-1}$ ), with a rapid PCR cycling time of $35 \mathrm{~min}$. The assay was validated with two EUROHEP HBV DNA standards (ad and ay subtypes) and exhibited low intra-assay $(<6 \%)$ and inter-assay $(<16 \%)$ variation for both subtypes over the complete range of 7 orders of magnitude. The assay was evaluated clinically using serum samples from $120 \mathrm{HBsAg}^{+}$individuals and 45 healthy controls who were negative for both $\mathrm{HBsAg}$ and anti-HBc. Levels of HBV DNA were measured in these samples using both the LC-PCR and Digene Hybrid Capture II HBV DNA (HCII) assays. The prevalence rates for $\mathrm{HBV}$ DNA in the $\mathrm{HBsAg}^{+}$serum samples were respectively $95 \%$ $(114 / 120)$ and $56 \%(67 / 120)$ by LC-PCR and HCII $(P<0.01)$. All 67 HCll-positive samples tested positive with LC-PCR, while the 47 discordant samples showed low levels of HBV DNA (down to 265 copies $\mathrm{ml}^{-1}$ ), detectable only by the more sensitive LC-PCR assay. Levels of HBV DNA as measured by the two assays showed good correlation $(r=0.902 ; P<0.001)$. The level of HBV DNA was significantly higher in $\mathrm{HBeAg}^{+}$than anti- $\mathrm{HBe}^{+}$samples (median $1.5 \times 10^{7}$ vs $4.6 \times 10^{4}$ copies $\mathrm{ml}^{-1} ; P<0.01$ ). It is concluded that this LC-PCR assay is clinically useful for the rapid, sensitive and accurate measurement of HBV DNA.
\end{abstract}

\section{INTRODUCTION}

Hepatitis B virus (HBV) remains an important cause of acute and chronic hepatitis, cirrhosis and hepatocellular carcinoma in endemic areas. Although the incidence of new infections has decreased after the introduction of vaccination programmes, HBV infection remains an important global health problem, with the number of chronic HBV carriers exceeding 350 million worldwide (Lee, 1997).

There is increasing evidence that measuring the level of HBV DNA in serum is useful in monitoring the efficacy of antiviral therapy, detecting the occurrence of drug-resistant mutants and detecting relapse after discontinuing antiviral therapy (Chan et al., 1998, 2002; Lai et al., 1998; Omata, 1998). Assays to quantify HBV DNA that are currently available commercially are based on either direct nucleic acid hybridization (Hendricks et al., 1995; Ho \& Chan, 2000; Lai et al., 1999) or competitive PCR (Kessler et al., 1998; Noborg et al., 1999). Amongst the former, we and others have reported the

Abbreviations: CV, coefficient of variation; FRET, fluorescence resonance energy transfer; HBV, hepatitis B virus; HCll, Digene Hybrid Capture II; LC-PCR, LightCycler PCR. superiority of the Hybrid Capture II HBV DNA test (HCII) (Digene Corp.) over other non-PCR-based assays in terms of accuracy and sensitivity (Ho et al., 1999; Ho \& Chan, 2000; Niesters et al., 2000). To date, although PCR-based assays have increased sensitivity, the technical complexity, susceptibility to contamination and more variable reproducibility of results with these assays have hindered their application in clinical practice (Kaneko et al., 1990; Quint et al., 1995).

Recent advances in PCR instrumentation and the capacity for simultaneous fluorimetric detection of PCR amplification products have enabled real-time kinetic analysis of the latter (Higuchi et al., 1992; Holland et al., 1991). Since amplification, measurement and quantification of PCR product occur simultaneously in the same closed reaction vessel, the need for post-PCR manipulations is obviated and the risk of PCR product carry-over contamination is minimized. Real-time PCR technology has been used to measure HBV DNA in serum using the TaqMan probe in the ABI Prism 7700 sequence detector (Perkin Elmer Applied Biosystems) (Abe et al., 1999; Loeb et al., 2000; Pas et al., 2000; Weinberger et al., 2000). In the present study, we have developed a rapid, specific and highly sensitive real-time PCR 
assay for HBV DNA based on the fluorescence resonance energy transfer (FRET) principle, with a pair of fluorescent hybridization probes and the LightCycler system (LC-PCR) (Roche Diagnostics). The accuracy, intra-assay and interassay variability and the detection range for this novel assay were examined, together with validation using EUROHEP HBV DNA standards. Also, the clinical performance of the LC-PCR was compared with that of the commonly used HCII test.

\section{METHODS}

Blood samples and standards. Serum samples from $120 \mathrm{HBsAg}^{+}$ patients and $45 \mathrm{HBsAg}^{-}$and anti- $\mathrm{HBc}^{-}$healthy blood donors were assayed for HBV DNA by both the LC-PCR and HCII assays. The $\mathrm{HBsAg}^{+}$patients were randomly included from chronic $\mathrm{HBV}$ carriers attending follow-up for serial monitoring of liver status. Blood samples were centrifuged within $4 \mathrm{~h}$ to obtain the serum fractions, which were then divided into aliquots and kept at $-80{ }^{\circ} \mathrm{C}$ before testing. Serological tests for HBsAg were performed with a commercial microparticle enzyme immunoassay (AxSym; Abbott Laboratories). Two EUROHEP standards were included (kindly provided by Dr W. H. Gerlich, University of Giessen, Germany) with HBV DNA concentrations of $2.7 \times 10^{9}$ and $2.6 \times 10^{9}$ copies $\mathrm{ml}^{-1}$ of serotypes ad and $a y$, respectively (Heermann et al., 1999).

HCII assay. The HCII ('standard') assay (Digene Corp.) quantified HBV DNA by solution hybridization, immunocapture and chemiluminescent signal detection. The assay protocol followed the manufacturer's instructions. Briefly, $30 \mu \mathrm{l}$ denaturing reagent was added to each microplate well containing $30 \mu \mathrm{l}$ of test samples or HBV DNA standards $\left(0-6000 \mathrm{pg} \mathrm{ml}^{-1}\right)$. The plate was incubated at $65^{\circ} \mathrm{C}$ for $30 \mathrm{~min}$ to allow lysis of HBV and DNA denaturation. RNA-DNA hybridization was achieved by adding $30 \mu \mathrm{l}$ RNA probe (specific for $\mathrm{HBV}$ ad and ay strains) to each well and incubating at $65^{\circ} \mathrm{C}$ for $60 \mathrm{~min}$. An aliquot $(75$ $\mu \mathrm{l})$ of the hybrid-containing solution was then transferred into RNADNA capture wells and shaken (Thermolyne Maxi-Mix III) at 1100 r.p.m. at room temperature for $60 \mathrm{~min}$. The solution in the wells was then removed by aspiration. An aliquot $(75 \mu \mathrm{l})$ of alkaline phosphataseconjugated antibodies to RNA-DNA hybrids was added to each well and incubated at room temperature for $30 \mathrm{~min}$. After six washings, $75 \mu \mathrm{l}$ chemiluminescent substrate was added and light emission after $15 \mathrm{~min}$ was measured with a chemiluminometer (DML 2000 Luminometer; Digene Corp.). Results were expressed in $\mathrm{pg} \mathrm{ml}^{-1}$ according to the plot of standards. The sensitivity according to the manufacturer was $0.5 \mathrm{pg}$ or $1.42 \times 10^{5}$ copies $\mathrm{ml}^{-1}$. We have previously reported an evaluation of this assay (Ho et al., 1999).

LC-PCR assay. Nucleic acid was extracted from $200 \mu \mathrm{l}$ serum and Digene Calibrator 5 using the QIAamp DNA Blood Mini kit (Qiagen) according to the manufacturer's protocol. DNA was eluted from the QIAamp spin column with $50 \mu \mathrm{l}$ distilled water, which served as the template for the LC-PCR assay. This DNA preparation had a concentration factor of 4 and a yield of $83 \pm 3 \%$ compared with the original amount of DNA in the sample. Calibrator 5 from the HCII assay, which contained $1.7 \times 10^{9}$ copies $\mathrm{ml}^{-1}\left(6000 \mathrm{pg} \mathrm{ml}^{-1}\right) \mathrm{HBV}$ plasmid DNA, was used to prepare the calibration curve for the LC-PCR assay, with a range from $10^{1}$ to $10^{8} \mathrm{HBV}$ DNA copies per reaction. The Qiagen DNA extraction step was performed on this Calibrator 5 standard as on the other samples to ensure parity of nucleic acid yield. In addition, this step removed the sodium azide used as a preservative in the Calibrator 5 standard, which might affect the PCR.

PCR was performed using a Roche Diagnostics LightCycler and the fluorescent signal of the PCR products after each cycle was monitored continuously by the FRET principle with a pair of fluorescent hybridization probes (Espy et al., 2000; Ghosh et al., 1994). We used a set of primers for the HBV core region (BcP1, 5'-ACCACC AAATGCCCCTAT-3'; BcP2, 5'-TTCTGCGACGCGGCGA-3'), according to published nested PCR protocols (Chung et al., 1993; Ho et al., 1999), which yielded a $130 \mathrm{bp}$ product. The donor fluorescein probe (HBVcD, 5'-GAGTTCTTCTTCTAGGGGACCTGC-fluorescein-3') and the acceptor LightCycler-Red 640 (LCRed) probe (HBVcA, 5'-LCRed-TCGTCGTCTAACAACAGTAGTTTCCG-phosphate-3') directed to the $130 \mathrm{bp}$ product were designed according to the manufacturer's guidelines (Roche). Aliquots of $10 \mu \mathrm{l}$ of the extracted nucleic acid template and $10 \mu \mathrm{l}$ of a reaction mixture containing $2 \mu \mathrm{l}$ $10 \times$ LightCycler FastStart DNA Master hybridization probes (Roche), $1 \mu \mathrm{M} \mathrm{BcP} 1,1 \mu \mathrm{M} \mathrm{BcP} 2,0 \cdot 3 \mu \mathrm{M}$ HBVcD donor probe, $0 \cdot 3 \mu \mathrm{M} \mathrm{HBVcA}$ acceptor probe and $5 \mathrm{mM} \mathrm{MgCl} 2$ were added to each capillary. All capillaries were sealed and then centrifuged briefly before amplification in the LightCycler. The PCR protocol consisted of an initial step at $95{ }^{\circ} \mathrm{C}$ for $10 \mathrm{~min}$ for activation of the FastStart Taq DNA polymerase, followed by 45 cycles of $0 \mathrm{~s}$ (hold time on reaching temperature) denaturation at $95^{\circ} \mathrm{C}, 12 \mathrm{~s}$ annealing at $60^{\circ} \mathrm{C}$ and $12 \mathrm{~s}$ extension at $72{ }^{\circ} \mathrm{C}$. The temperature transition rate was $20^{\circ} \mathrm{C} \mathrm{s}^{-1}$ for all steps. Fluorescence data were acquired once each cycle at the end of the annealing phase with detection channel setting at F2/F1.

For data analysis, baseline adjustment was carried out in the 'proportional' mode and fluorescence curve analyses were carried out in the 'fit points' mode of the LightCycler software. Positive results obtained in the LC-PCR assay using fluorescent hybridization probes were characterized by a sigmoid curve, showing an initial, rapid, exponential increase in fluorescence signal followed by a plateau. Negative reactions did not show any increase in fluorescence signal. A standard curve was created automatically with the LightCycler software in each run by plotting the threshold cycle number against the copy numbers of each standard and quantification of HBV DNA for unknown samples was inferred from the regression line.

Statistics. Determination of the inter- and intra-assay coefficients of variation $(\mathrm{CV})$ of the LC-PCR in testing the EUROHEP standards at different dilutions and the $x y$ scatter plot, Spearman's correlation $(r)$ and logarithmic transformation of the readings for comparison of the HCII and LC-PCR assays were done by using the SPSS software (version 8.0, SPSS Inc.). Comparisons between $\mathrm{HBeAg}^{+}$and anti- $\mathrm{HBe}^{+}$subjects were by $\chi^{2}$ and Mann-Whitney tests.

\section{RESULTS}

The time required to perform the LC-PCR assay was less than $2.5 \mathrm{~h}$, including extraction of DNA from serum samples (completed in $1.5 \mathrm{~h}$ ) and real-time PCR cycling and data analysis on the LightCycler (40 min). To determine the linear range and sensitivity of the LC-PCR assay, serial 10 -fold dilutions of HBV DNA samples prepared with the Digene Calibrator 5 were tested in triplicate ( 10 copies per reaction) or duplicate $\left(10^{2}-10^{8}\right.$ copies per reaction). All samples with concentrations ranging from $10^{1}$ to $10^{8}$ copies per reaction tested positive with LC-PCR, with typical sigmoid fluorescence curves (Fig. 1). The detection limit was 10 copies per reaction $\left(250\right.$ copies $\left.\mathrm{ml}^{-1}\right)$, while no amplification product was obtained with the negative control. There was a linear correlation between the cycle number $(y)$ and the input concentration (copies per reaction) of HBV DNA template (x) $\left[r=1.0 ; \quad y=-3.533 \log _{10}(x)+42 \cdot 73\right]$. This standard curve over the $8 \log _{10}$ dynamic range was used in the quantification of HBV DNA in the test samples. 


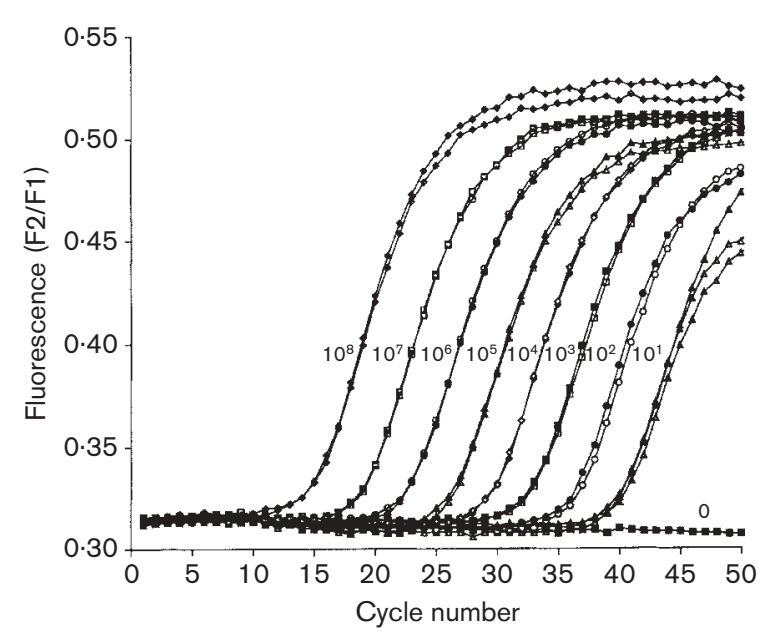

Fig. 1. Quantification of HBV DNA with fluorescent hybridization probes on the LightCycler. Serial 10-fold dilutions from $10^{1}$ to $10^{8}$ copies of plasmid HBV DNA per reaction in duplicate or triplicate were analysed with the LightCycler. Typical amplification curves are shown, which illustrate the relationship between fluorescence as measured in channel F2/F1 and the number of cycles. No amplification was noted in the 0 copies per reaction (negative control) capillaries.

To determine the accuracy and CV of the LC-PCR assay at different HBV DNA concentrations, EUROHEP standards from a single extraction were tested in three separate runs, both undiluted and in sequential 10-fold dilutions. An almost linear results curve against the theoretical values was obtained over the complete range of 8 orders of magnitude for both ad and ay serotypes, with intra-assay CV of $6 \%$ and inter-assay CV of $16 \%$ (Fig. 2). All samples with ad subtype concentration $\geqslant 270$ copies $\mathrm{ml}^{-1}$ or ay subtype concentration $\geqslant 260$ copies $\mathrm{ml}^{-1}$ tested positive, confirming the sensitivity limit of 250 copies $\mathrm{ml}^{-1}$ indicated by the standard curve (Fig. 2).

To examine the clinical performance of the LC-PCR assay, HBV DNA concentrations were measured in serum samples from $120 \mathrm{HBsAg}^{+}$patients and $45 \mathrm{HBsAg}^{-}$healthy controls and the results were compared with those determined using the HCII assay. The seroprevalence for HBV DNA among the $\mathrm{HBsAg}^{+}$patients was 114/120 (95\%) by LC-PCR and 67/120 $(56 \%)$ by HCII $(P<0 \cdot 01)$ (Table 1$)$. All 67 HCII-positive samples yielded positive results with the LC-PCR assay, and the log-transformed HBV DNA concentrations obtained with the two assays demonstrated a good correlation $(r=0.902 ; P<0.001)$. The 47 discordant samples from $\mathrm{HBsAg}^{+}$patients that tested negative by HCII (i.e. $<1.42$ $\times 10^{5}$ copies $\mathrm{ml}^{-1}$ ) but positive by LC-PCR contained HBV DNA at low concentrations, down to 265 copies $\mathrm{ml}^{-1}$ (Fig. 3). All 45 samples from healthy controls tested negative by both assays, thereby yielding specificity rates of $100 \%$.

Of the $120 \mathrm{HBsAg}^{+}$patients, $54(45 \%)$ were positive for HBeAg and $66(55 \%)$ were positive for anti-HBe, and the

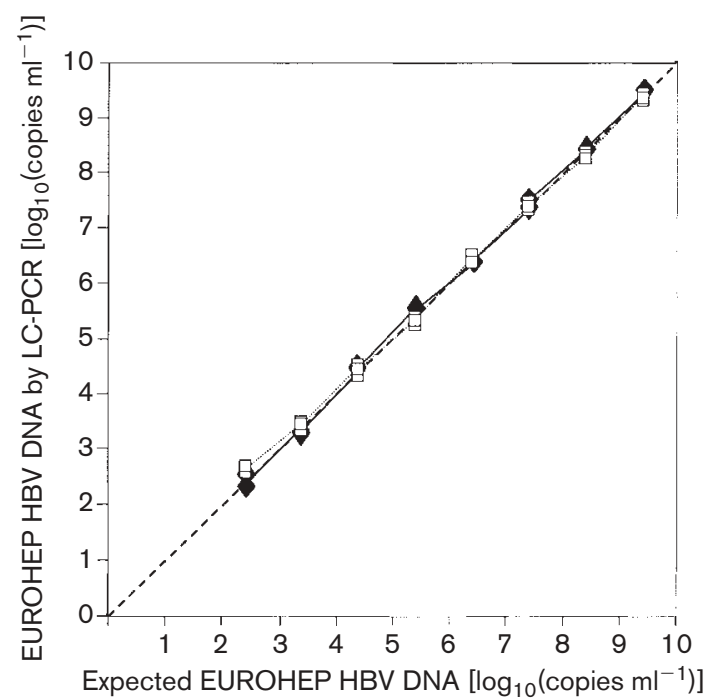

Fig. 2. Testing of EUROHEP standards with the LC-PCR assay. Serial 10-fold dilutions were made from EUROHEP standards of subtype ad $(\bullet)$ and ay $(\square)$. Each sample was analysed in triplicate in three runs. The expected (input) HBV DNA concentration was plotted against the mean concentration of triplicate runs as measured by LCPCR. The dashed line represents the theoretical curve.

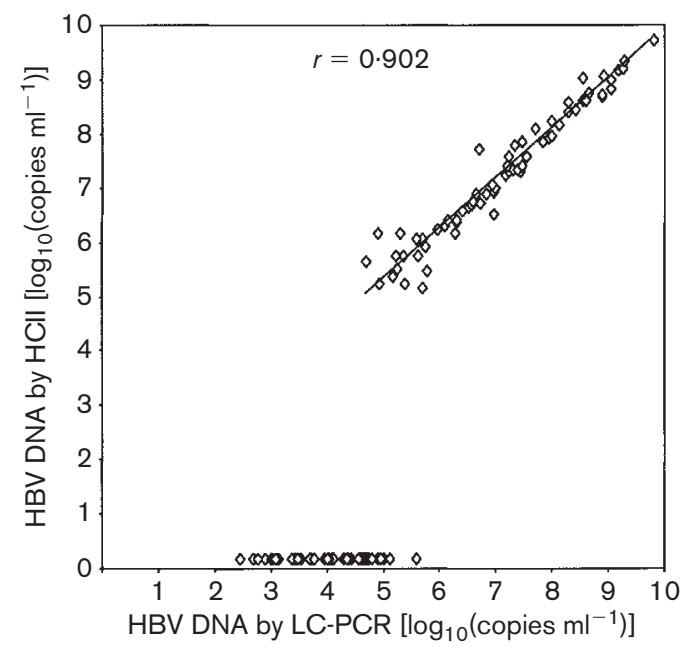

Fig. 3. Log-log plot of HBV DNA concentrations in 114 samples from $\mathrm{HBsAg}{ }^{+}$patients as measured by LC-PCR or HCll assays. Good correlation was observed between results obtained with the two assays for the 67 concordant positive samples. Forty-seven samples tested negative by HCIl but had detectable HBV DNA by LC-PCR.

prevalence of HBV DNA by LC-PCR was similar in the two groups (100 and $95 \%$, respectively; not significant). In contrast, the HCII assay failed to detect HBV DNA in a considerable number of anti- $\mathrm{HBe}^{+}$patients ( 89 vs $29 \%$; $P<0.001$ ) (Table 1). The HBV DNA concentration, as determined by LC-PCR, was significantly higher in $\mathrm{HBeAg}^{+}$ 
Table 1. Detection of HBV DNA by LC-PCR and HCll assays and the relationship to $\mathrm{HBeAg} / \mathrm{anti}-\mathrm{HBe}$ status

Serum samples from $120 \mathrm{HBsAg}^{+}$subjects were tested. Results are numbers (percentages) testing positive for HBV DNA.

\begin{tabular}{|lccl|}
\hline Assay & $\begin{array}{c}\text { All } \\
(\boldsymbol{n}=\mathbf{1 2 0})\end{array}$ & $\begin{array}{c}\mathbf{H B e A g}^{+} \\
(\boldsymbol{n}=\mathbf{5 4})\end{array}$ & $\begin{array}{c}\text { Anti-HBe }^{+} \\
(\boldsymbol{n}=\mathbf{6 6})\end{array}$ \\
\hline LC-PCR & $114(95)^{a \star}$ & $54(100)$ & $60(95)$ \\
HCII & $67(56)^{a}$ & $48(89)^{b}$ & $19(29)^{b}$ \\
\hline
\end{tabular}

${ }^{*}$ Values with the same superscript are significantly different at $P<0 \cdot 01$ (a) or $P<0.001(b)$.

patients compared with those positive for anti-HBe (median $1.5 \times 10^{7}$ vs $4.6 \times 10^{4}$ copies $\mathrm{ml}^{-1}$, range $1100-6.6 \times 10^{9}$ and $<250-1.8 \times 10^{9} ; P<0.05$ ) (Fig. 4).

\section{DISCUSSION}

Recent advances in PCR technology allow continuous measurement of the fluorescence emitted during amplicon production at each PCR cycle. The fluorescent reporters include the SYBR Green dye for sequence-non-specific detection of double-stranded DNA or TaqMan probe, hybridization probes and molecular beacons for targetsequence-specific detection. Although inexpensive and easy to use, the SYBR Green dye may produce false-positive signals after 30 cycles of real-time PCR and is therefore not applicable to the measurement of serum HBV DNA at $<10^{5}$ copies $\mathrm{ml}^{-1}$, except with the addition of a second-round nested reaction (Brechtbuehl et al., 2001), which would be time-consuming and might increase the risk of PCR product carry-over contamination.

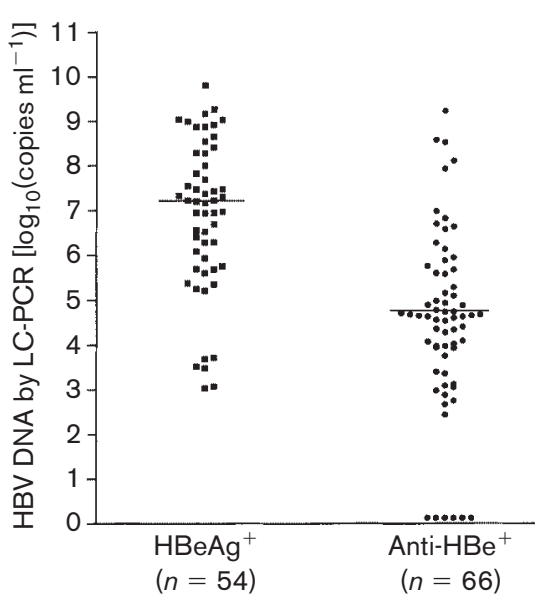

Fig. 4. $\mathrm{HBV}$ DNA concentration in serum samples from $120 \mathrm{HBsAg}^{+}$ subjects in relation to $\mathrm{HBeAg} / a n t i-H B e$ status. The level of HBV DNA was significantly higher in $\mathrm{HBeAg}^{+}$subjects compared with those positive for anti-HBe (median values are indicated by horizontal rules).
We have designed the sequences of the donor $(\mathrm{HBVcD})$ and acceptor (HBVcA) hybridization probes on the basis of a set of primers $(\mathrm{BcP} 1$ and $\mathrm{BcP} 2)$ that we have used for more than 8 years in our in-house HBV nested PCR assay (Chung et al., 1993; Ho et al., 1999). The upstream probe is labelled at the $3^{\prime}$-end with fluorescein and the downstream probe at its $5^{\prime}$ end with LCRed. As the PCR products are made, FRET from fluorescein (donor) to LCRed (acceptor) results in an increase in LCRed signal. The LCRed signal is determined by the amount of product at the end of each PCR cycle, and the first significant increase in signal during the exponential phase (i.e. the threshold cycle) correlates with the initial amount of target DNA template. Our probes have been designed to anneal one base apart on the target $130 \mathrm{bp}$ amplicon in order to achieve maximum FRET signal production.

The use of the QIAamp DNA Blood kit for nucleic acid extraction minimizes contamination and ensures reproducibility of yield, both important properties of quantitative assays. The LightCycler FastStart DNA Master hybridization probe also contributes to the accuracy of the LC-PCR assay, since the constituent polymerase (a modified form of thermostable recombinant Taq DNA polymerase) in this ready-to-use 'hot-start' reaction mixture is only activated after heating at $95^{\circ} \mathrm{C}$ for $10 \mathrm{~min}$ has removed the blocking groups.

The two EUROHEP reference standards have been used for standardization of HBV DNA test kits and in quality-control trials (Heermann et al., 1999; Niesters et al., 2000). Although it is theoretically better to use a biological standard, such as the HBV genome, rather than a plasmid calibrator, the limited supply of the EUROHEP references presents a major hindrance to their routine use in assays for clinical service. Therefore, we have used the readily available calibrator of the Digene assay as a standard in the LC-PCR assay and have validated the assay with the EUROHEP standards. Our results demonstrated linearity over the entire $8-\log _{10}$ detection range, with low CV for both EUROHEP ad and ay serotypes. Evaluation of clinical samples from $\mathrm{HBsAg}^{+}$ patients and $\mathrm{HBsAg}^{-}$controls showed that the LC-PCR assay was highly specific. Its results correlated well with their HCII counterparts, thereby facilitating direct comparison of data obtained with different assays. Of particular significance is the more than 500 -fold increase in sensitivity with the LCPCR assay compared with the standard HCII test, with the ability to detect HBV DNA at levels as low as 250 copies $\mathrm{ml}^{-1}$. This presents a distinct clinical advantage in patients receiving antiviral medications, which helps to ensure adequate suppression of virus replication, in order to detect relapse early or to monitor for the emergence of drug-resistant HBV mutants. In this context, there are recent reports that have demonstrated a relationship between virus load and the propensity to develop drug-resistant mutants (Puchhammer-Stockl et al., 2000). Besides quantification, another application of fluorimetric real-time PCR assay with 
the LightCycler has been the detection of emergence of drugresistant HBV mutants (YMDD motifs) in patients during lamivudine therapy (Cane et al., 1999; Whalley et al., 2001).

We have shown that the level of HBV DNA is generally higher in $\mathrm{HBeAg}^{+}$subjects compared with those who are positive for anti-HBe and that the improved sensitivity of LC-PCR offers a definite advantage in the detection of the relatively lower levels of viraemia in the latter group. Nevertheless, there is marked individual variation, and the virus load can be high in some anti- $\mathrm{HBe}^{+}$patients. In this regard, five anti$\mathrm{HBe}^{+}$patients had HBV DNA levels higher than the median level in the $\mathrm{HBeAg}^{+}$group. Two of the five patients were renal transplant recipients and the other three were nonimmunosuppressed patients with persistently abnormal liver biochemistry. These results suggest that HBeAg/anti-HBe status is not a reliable surrogate marker for virus replication or disease activity (Chan et al., 2002).

Our results demonstrate that the LC-PCR assay has a broad quantification range from 250 to $2.5 \times 10^{9}$ copies $\mathrm{ml}^{-1}$ and low intra-assay and inter-assay CVs, similar to assays using the TaqMan probe and ABI PRISM (Abe et al., 1999; Loeb et al., 2000; Pas et al., 2000; Weinberger et al., 2000). Other LightCycler-based quantitative HBV DNA assays have used the standard from the Chiron HBV DNA Quantiplex assay and offer detection ranges from 10 to $10^{10}$ copies per reaction (Jardi et al., 2001; Paraskevis et al., 2002). Paraskevis et al. (2002) compared home-made HBV DNA plasmid and pooled patient sera with high HBV DNA levels as standards and concluded that the two yielded very similar results. The ABI PRISM 7700 detector has the advantage of simultaneous analysis of up to 96 samples, compared with 32 samples with the LightCycler. On the other hand, the turn-around time of the LC-PCR assay is less than $2.5 \mathrm{~h}$, compared with $4 \mathrm{~h}$ required for other real-time PCR assays. The reagents of both real-time PCR methods are less expensive than those of the commercial HBV DNA kits. Hence, the presently reported LC-PCR assay represents another option amongst the choices for real-time PCR assays; users can therefore select according to their particular requirements.

In conclusion, this LC-PCR assay permits sensitive and accurate quantification of serum HBV DNA over a wide range within $2.5 \mathrm{~h}$ and has potential for both research and clinical use, in view of the increasing number of patients being monitored for changes in virus load.

\section{REFERENCES}

Abe, A., Inoue, K., Tanaka, T., Kato, J., Kajiyama, N., Kawaguchi, R., Tanaka, S., Yoshiba, M. \& Kohara, M. (1999). Quantitation of hepatitis B virus genomic DNA by real-time detection PCR. J Clin Microbiol 37, 2899-2903.

Brechtbuehl, K., Whalley, S. A., Dusheiko, G. M. \& Saunders, N. A. (2001). A rapid real-time quantitative polymerase chain reaction for hepatitis B virus. J Virol Methods 93, 105-113.

Cane, P. A., Cook, P., Ratcliffe, D., Mutimer, D. \& Pillay, D. (1999). Use of real-time PCR and fluorimetry to detect lamivudine resistanceassociated mutations in hepatitis B virus. Antimicrob Agents Chemother 43, 1600-1608.
Chan, T. M., Wu, P. C., Li, F. K., Lai, C. L., Cheng, I. K. \& Lai, K. N. (1998). Treatment of fibrosing cholestatic hepatitis with lamivudine. Gastroenterology 115, 177-181.

Chan, T. M., Fang, G. X., Tang, C. S. O., Cheng, I. K. P., Lai, K. N. \& Ho, S. K. N. (2002). Preemptive lamivudine therapy based on HBV DNA level in HBsAg-positive kidney allograft recipients. Hepatology 36, 1246-1252.

Chung, H. T., Lok, A. S. \& Lai, C. L. (1993). Re-evaluation of alphainterferon treatment of chronic hepatitis B using polymerase chain reaction. J Hepatol 17, 208-214.

Espy, M. J., Uhl, J. R., Mitchell, P. S., Thorvilson, J. N., Svien, K. A., Wold, A. D. \& Smith, T. F. (2000). Diagnosis of herpes simplex virus infections in the clinical laboratory by LightCycler PCR. J Clin Microbiol 38, 795-799.

Ghosh, S. S., Eis, P. S., Blumeyer, K., Fearon, K. \& Millar, D. P. (1994). Real time kinetics of restriction endonuclease cleavage monitored by fluorescence resonance energy transfer. Nucleic Acids Res 22, 31553159.

Heermann, K. H., Gerlich, W. H., Chudy, M., Schaefer, S. \& Thomssen, R. (1999). Quantitative detection of hepatitis B virus DNA in two international reference plasma preparations. Eurohep Pathobiology Group. J Clin Microbiol 37, 68-73.

Hendricks, D. A., Stowe, B. J., Hoo, B. S., Kolberg, J., Irvine, B. D., Neuwald, P. D., Urdea, M. S. \& Perrillo, R. P. (1995). Quantitation of HBV DNA in human serum using a branched DNA (bDNA) signal amplification assay. Am J Clin Pathol 104, 537-546.

Higuchi, R., Dollinger, G., Walsh, P. S. \& Griffith, R. (1992). Simultaneous amplification and detection of specific DNA sequences. Biotechnology 10, 413-417.

Ho, S. K. \& Chan, T. M. (2000). An overview of assays for serum HBV DNA. Clin Lab 46, 609-614.

Ho, S. K., Chan, T. M., Cheng, I. K. \& Lai, K. N. (1999). Comparison of the second-generation digene hybrid capture assay with the branched-DNA assay for measurement of hepatitis B virus DNA in serum. J Clin Microbiol 37, 2461-2465.

Holland, P. M., Abramson, R. D., Watson, R. \& Gelfand, D. H. (1991). Detection of specific polymerase chain reaction product by utilizing the $5^{\prime}-3^{\prime}$ exonuclease activity of Thermus aquaticus DNA polymerase. Proc Natl Acad Sci U S A 88, 7276-7280.

Jardi, R., Rodriguez, F., Buti, M., Costa, X., Cotrina, M., Valdes, A., Galimany, R., Esteban, R. \& Guardia, J. (2001). Quantitative detection of hepatitis B virus DNA in serum by a new rapid real-time fluorescence PCR assay. J Viral Hepat 8, 465-471.

Kaneko, S., Miller, R. H., Di Bisceglie, A. M., Feinstone, S. M., Hoofnagle, J. H. \& Purcell, R. H. (1990). Detection of hepatitis B virus DNA in serum by polymerase chain reaction. Application for clinical diagnosis. Gastroenterology 99, 799-804.

Kessler, H. H., Pierer, K., Dragon, E., Lackner, H., Santner, B., Stunzner, D., Stelzl, E., Waitzl, B. \& Marth, E. (1998). Evaluation of a new assay for HBV DNA quantitation in patients with chronic hepatitis B. Clin Diagn Virol 9, 37-43.

Lai, C. L., Chien, R. N., Leung, N. W. \& 9 other authors (1998). A oneyear trial of lamivudine for chronic hepatitis B. Asia Hepatitis Lamivudine Study Group. N Engl J Med 339, 61-68.

Lai, V. C., Guan, R., Wood, M. L., Lo, S. K., Yuen, M. F. \& Lai, C. L. (1999). Nucleic acid-based cross-linking assay for detection and quantification of hepatitis B virus DNA. J Clin Microbiol 37, 161-164.

Lee, W. M. (1997). Hepatitis B virus infection. N Engl J Med 337, 1733-1745.

Loeb, K. R., Jerome, K. R., Goddard, J., Huang, M., Cent, A. \& Corey, L. 
(2000). High-throughput quantitative analysis of hepatitis B virus DNA in serum using the TaqMan fluorogenic detection system. Hepatology 32, 626-629.

Niesters, H. G., Krajden, M., Cork, L., de Medina, M., Hill, M., Fries, E. \& Osterhaus, A. D. (2000). A multicenter study evaluation of the digene hybrid capture II signal amplification technique for detection of hepatitis B virus DNA in serum samples and testing of EUROHEP standards. J Clin Microbiol 38, 2150-2155.

Noborg, U., Gusdal, A., Pisa, E. K., Hedrum, A. \& Lindh, M. (1999). Automated quantitative analysis of hepatitis B virus DNA by using the Cobas Amplicor HBV monitor test. J Clin Microbiol 37, 2793-2797.

Omata, M. (1998). Treatment of chronic hepatitis B infection. N Engl J Med 339, 114-115.

Paraskevis, D., Haida, C., Tassopoulos, N., Raptopoulou, M., Tsantoulas, D., Papachristou, H., Sypsa, V. \& Hatzakis, A. (2002). Development and assessment of a novel real-time PCR assay for quantitation of HBV DNA. J Virol Methods 103, 201-212.

Pas, S. D., Fries, E., De Man, R. A., Osterhaus, A. D. \& Niesters, H. G.
(2000). Development of a quantitative real-time detection assay for hepatitis B virus DNA and comparison with two commercial assays. J Clin Microbiol 38, 2897-2901.

Puchhammer-Stockl, E., Mandl, C. W., Kletzmayr, J., Holzmann, H., Hofmann, A., Aberle, S. W., Heinz, F. X., Watschinger, B. \& Hofmann, H. (2000). Monitoring the virus load can predict the emergence of drugresistant hepatitis B virus strains in renal transplantation patients during lamivudine therapy. J Infect Dis 181, 2063-2066.

Quint, W. G., Heijtink, R. A., Schirm, J., Gerlich, W. H. \& Niesters, H. G. (1995). Reliability of methods for hepatitis B virus DNA detection. J Clin Microbiol 33, 225-228.

Weinberger, K. M., Wiedenmann, E., Bohm, S. \& Jilg, W. (2000). Sensitive and accurate quantitation of hepatitis B virus DNA using a kinetic fluorescence detection system (TaqMan PCR). J Virol Methods $85,75-82$.

Whalley, S. A., Brown, D., Teo, C. G., Dusheiko, G. M. \& Saunders, N. A. (2001). Monitoring the emergence of hepatitis B virus polymerase gene variants during lamivudine therapy using the LightCycler. J Clin Microbiol 39, 1456-1459. 